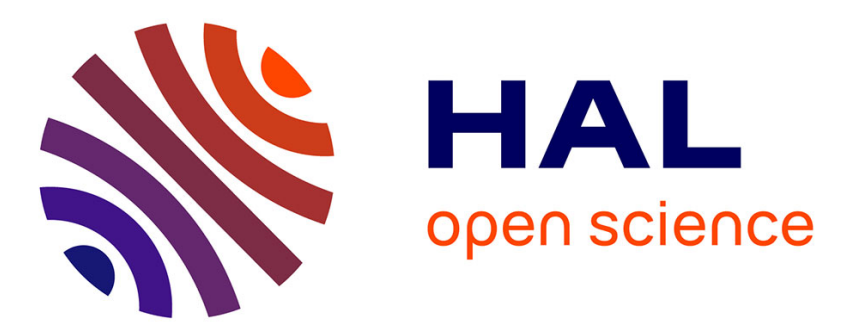

\title{
Observing plant roots in their environment: current imaging options and specific contribution of two-dimensional approaches
}

\author{
Alain Pierret, Claude Doussan, Emmanuelle Garrigues, John Mc Kirby
}

\section{To cite this version:}

Alain Pierret, Claude Doussan, Emmanuelle Garrigues, John Mc Kirby. Observing plant roots in their environment: current imaging options and specific contribution of two-dimensional approaches. Agronomie, 2003, 23 (5-6), pp.471-479. 10.1051/agro:2003019 . hal-00886199

\section{HAL Id: hal-00886199 https://hal.science/hal-00886199}

Submitted on 1 Jan 2003

HAL is a multi-disciplinary open access archive for the deposit and dissemination of scientific research documents, whether they are published or not. The documents may come from teaching and research institutions in France or abroad, or from public or private research centers.
L'archive ouverte pluridisciplinaire HAL, est destinée au dépôt et à la diffusion de documents scientifiques de niveau recherche, publiés ou non, émanant des établissements d'enseignement et de recherche français ou étrangers, des laboratoires publics ou privés. 


\title{
Observing plant roots in their environment: current imaging options and specific contribution of two-dimensional approaches
}

\author{
Alain PIERRET ${ }^{\mathrm{a}}$, Claude DoussAN ${ }^{\mathrm{b} *}$, Emmanuelle GARRIGUES ${ }^{\mathrm{b}}$, John Mc KIRBYa \\ ${ }^{a}$ CSIRO Land \& Water, GPO Box 1666, Canberra ACT, Australia \\ ${ }^{\mathrm{b}}$ INRA-CSE, Domaine Saint-Paul, Site Agroparc, 84914 Avignon Cedex 9, France
}

(Received 19 June 2002; accepted 28 January 2003)

\begin{abstract}
This paper provides an overview of current options for imaging roots in their environment. Our primary aim is to describe the potential and limitations of these techniques, rather than their physical principles. We primarily discuss two-dimensional imaging techniques which, while inherently limited by their 2-dimensional nature are technically simple, cheaper, more readily accessible, and offer larger fieldof-view or better resolution for a similar field-of-view than three-dimensional imaging techniques. We show that techniques involving microscopic or high-resolution X-ray imaging of roots in undisturbed soil samples have a considerable value because they can provide, at a scale which is not accessible by any other means, essential information on complex interactions between roots and soil structure. We also illustrate how 2D imaging techniques, based on either visible light or X-ray attenuation through thin growing containers (rhizotrons), can be used to study whole root systems. We conclude that, while fully appropriate 3D imaging tools will ultimately become available, in the meantime, two-dimensional techniques should be considered as relevant options for observing roots in their environment.
\end{abstract}

\section{D and 3D imaging / root system / root-soil interactions / water uptake}

Résumé - Observation des racines dans leur environnement : techniques d'imagerie actuelles et apports spécifiques des approches 2D. Cet article offre un inventaire des techniques d'imagerie actuellement disponibles pour l'observation des racines au sein de leur environnement. Le propos est avant tout d'informer le lecteur sur le potentiel et les limites des techniques et non sur leurs principes physiques. D'autre part, l'accent est mis sur l'apport spécifique des méthodes 2D : en dépit des limitations et biais qui leur sont inhérents, ces méthodes offrent en effet, par rapport aux outils 3D actuellement disponibles, des avantages tels qu'un grand champ d'observation ou une résolution supérieure à champ d'observation équivalent, ou encore, une mise en œuvre simplifiée et un coût réduit. Ainsi, la microscopie et la radiographie X à haute résolution sont très attractives car elles permettent d'étudier, à une échelle qui demeure hors de la portée des méthodes 3D, les interactions complexes entre racines et structure du sol. On montre par ailleurs que les méthodes 2D basées sur l'atténuation de lumière visible ou de rayons $\mathrm{X}$ s'avèrent très utiles pour étudier le fonctionnement de systèmes racinaires entiers en rhizotrons. S'il ne fait guère de doute qu'à relativement court terme, les progrès accomplis dans le domaine de l'imagerie 3D aboutiront à la mise au point d'outils parfaitement adaptés à l'observation non destructive des racines dans leur environnement, il n'en reste pas moins que, dans l'attente de tels outils, les techniques 2D continueront de faire progresser notre connaissance des racines et de leur fonctionnement.

imagerie 2D et 3D / système racinaire / interactions sol-racines / prélèvement d'eau

\section{INTRODUCTION}

The above ground parts of plants have been well studied but roots have received much less attention. A simple reason for this apparently limited interest in roots is purely technical: roots being tightly enmeshed in the opaque soil matrix, it is extremely difficult to observe them in situ [10]. Under field conditions, roots are exposed to a very heterogeneous environment: the physical, chemical and biological properties of soil can vary greatly within a few millimeters, e.g. [39, 46], and affect root growth, either beneficially or detrimentally, at a very local scale. Interactions between roots and soil structure and the resulting effects on root physiology remain poorly understood. Such knowledge is however essential as it is likely that plant performance is linked to the precise location of roots with respect to soil structure features $[35,36]$ as well as the micro-environment surrounding the roots [32]. For example, observations based on physical separation of roots from soil, 
suggest that although roots growing down macropores may be able to access more water and nutrient from depth, this apparent advantage is most likely offset by poor soil-contact along much of the root and impeded lateral growth [44].

The simplest and most commonly used method of measuring roots is by washing auger sampled cores. This method can be used to determine root length density, a key parameter in many models of root water extraction. However, it is well documented that many fine roots are broken off and washed away with the soil, leading to biased estimates, e.g. [27]. Other simple invasive methods such as trench profile methods are suitable for observing the spatial distribution of roots and, to some extent, the root environment. However, such trench methods do not allow direct assessment of root growth and poor visible contrast between roots and the soil matrix may affect the results of root mapping [21]. Alternatively the mini-rhizotron method is a relatively standard option for assessing root growth, but there are concerns about roots growing preferentially around mini-rhizotron tubes [13].

In this paper we examine the current options for imaging roots and their environment. We deliberately give little description of the principles behind these techniques and concentrate on their suitability and limitations, in the specific context of root-soil studies. Three-dimensional imaging techniques are only briefly dealt with in a general discussion since they have received reasonable coverage in recent literature, e.g. [2]. Priority is given to the discussion of two-dimensional imaging and we consider and discuss in greater detail techniques we have recently experimented with, namely: (i) high-resolution X-ray imaging of roots in undisturbed, resin impregnated soil samples; (ii) X-ray imaging of root growth and response to soil constraints in thin containers and (iii) light transmission imaging of root water uptake in thin containers. We show that these technically simple alternatives to 3-dimensional imaging are cheaper, more readily accessible and generally offer a larger field-of-view or better resolution for a similar field-of-view.

\section{TWO-DIMENSIONAL DESTRUCTIVE/INVASIVE TECHNIQUES}

\subsection{Microscopy of roots in undisturbed soil samples}

As far back as 1954, Barley [5] used optical microscopy to derive soil density profiles around roots grown in sandy loams. During the last decade, substantial progress in observing/ measuring the spatial relations between roots and soil was achieved via optical microscopy. Using thin sections of undisturbed soil samples van Noordwijk et al. [47] and Kooistra et al. [24] demonstrated that it is possible to qualitatively investigate the degree of contact between roots and soil, an important parameter influencing oxygen, water and nutrient uptake [12]. Similar studies on polished sections of undisturbed soil demonstrated, at a slightly coarser scale, non-random relationships between roots and soil structural features such as macropores [25, 42, 43].

At a finer scale, electron microscopy of thin sections has been used to study physical interactions between roots and soil. For example, using backscattered electron images,
Bruand et al. [8] showed that by rearranging the packing of soil skeleton grains, root radial growth can cause local changes in bulk density of up to $0.26 \mathrm{Mg} \cdot \mathrm{m}^{-3}$.

Examination of fresh, undisturbed samples frozen in the field, by cryo-Scanning Electron Microscopy (cryo-SEM) coupled with X-ray microanalysis is leading to advances in the study of the water relations at the soil-root interface, as well as feed-forward/feedback effects between roots and their rhizospheres [32]. One example which clearly demonstrates the potential of this technique was the finding of so-called rhizosheaths [48], zones of enhanced and stabilized soil aggregation around roots of many grass species including cereals. From a functional point of view, rhizosheaths have been shown to considerably increase the contact between roots and soil. Cryo-SEM studies demonstrated that although rhizosheaths have an inherent porosity, parts of root hairs constantly stay in contact with rhizosheath soil via surrounding mucilage expanded by exuded water [33].

The main hindrance to a wider adoption of these microscopic techniques results either from the cost of specialized laboratory equipment and labour required for sample preparation (thin sections), or from the cost of analytical equipment (cryo-SEM). However, these methods can provide essential information on how plant roots grow and function under field conditions, at a scale which is not accessible by any other means.

\subsection{X-ray imaging of roots in undisturbed, resin impregnated soil samples}

This method was first introduced by Moran et al. [34]. To some extent, it can be seen as an X-ray equivalent of the thin section method described in the previous section, with the advantage of providing a quantified description of the soil structure as a density/porosity field. X-rays emitted by a microfocus source (i.e. a source with a small focal spot of about $10-20 \mu \mathrm{m}$ ) are attenuated differently by sample features such as soil structural elements with different densities. In addition to this differential attenuation, materials with a phase contrast such as the interface between soil and roots cause a slight refraction of the X-rays [49]. This enhances the attenuation contrast between soil and roots, and thus leads to improved image clarity. The resulting images permit ready discrimination of the roots. Samples observed are typically $1 \mathrm{~mm}$ thick sections of resin impregnated soil collected in the field. Due to the cone-shaped X-ray beam, projected images can be directly magnified on the image detector. Possible imaging configurations are many: the most commonly used for this application yields images of a $66 \mathrm{~mm}$ square field-ofview with a $17.5 \mu \mathrm{m}$ pixel size. With high-flux sources now available, exposure times are of the order of a few seconds. Different types of image detectors can be used, such as photographic plates, charge-coupled device (CCD) cameras coupled with phosphor screens or phosphor image plates. Once acquired, the images can be transformed into soil density fields according to the calibration procedure of Bresson and Moran [7]. The images are subsequently processed and various attributes such as the root length density, root diameter or estimates of the spatial association of roots with the least dense areas of soil determined. 
a
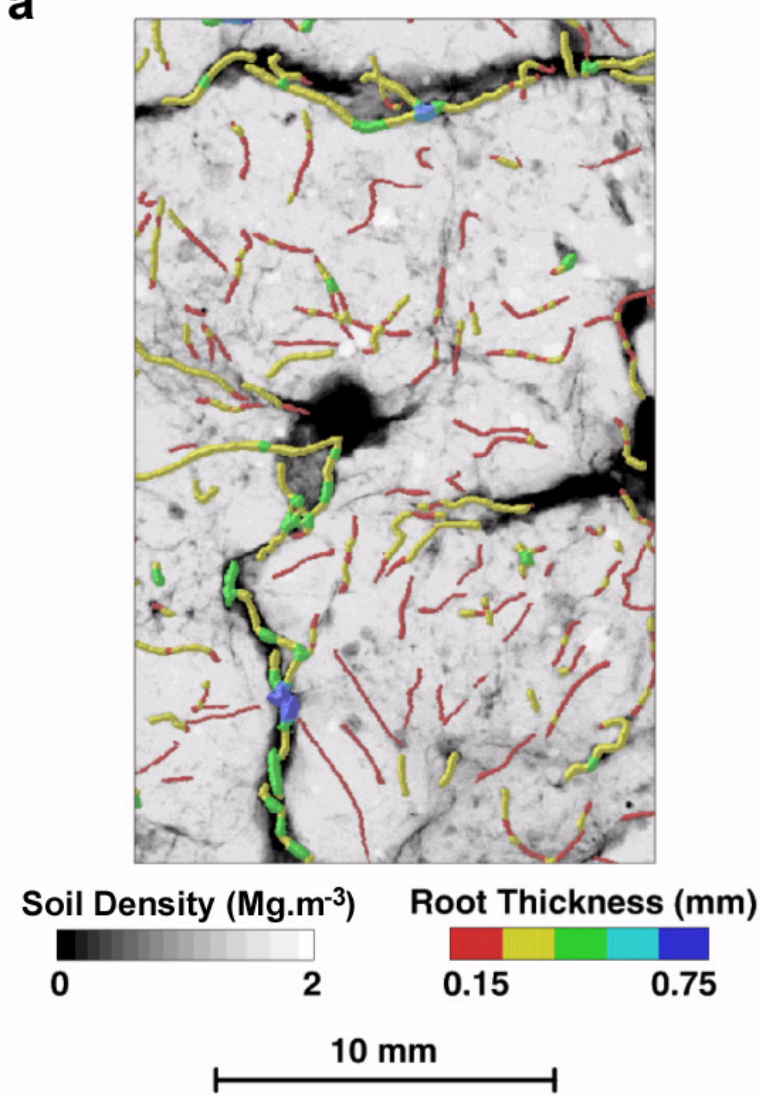

b

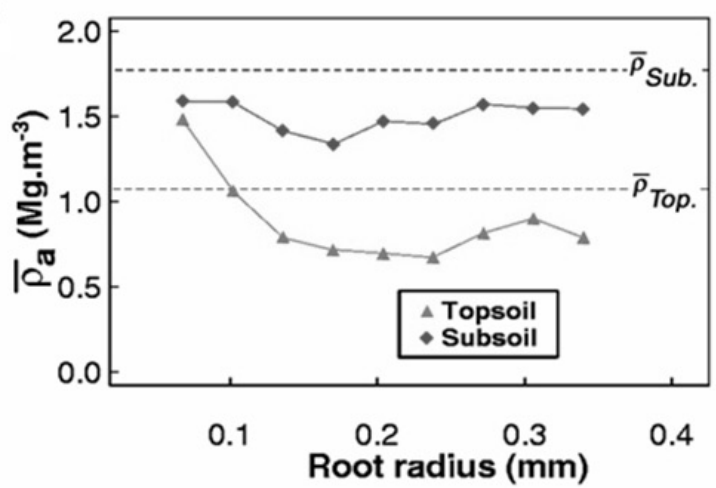

Figure 1. (a) Image of roots growing in structured subsoil (vertical section), showing the soil density and root diameter. (b) Relationship between bulk density of soil in contact with roots and root radius. This indicates that, for the case study discussed under Section 2.3, in both the topsoil and subsoil, roots grew preferentially in soil less dense than the average bulk densities of the subsoil and the topsoil (represented by the thick and thin dotted lines, respectively). (Redrawn from [34]). Figure 1(a) is available in colour at: www.edpsciences.org/agro/.

To assess the potential of this method, undisturbed samples were collected from a Natric Palexeralf [40] under a wheat crop. After transportation to the laboratory, samples were impregnated with polyester resin and sectioned both vertically and horizontally. It could be shown that, under this soil/crop combination, roots grew preferentially in looser soil but not necessarily in the macropores (Figs. 1a, b). This confirmed previous results [42], obtained from observation of the surface of the same soil sections using optical microscopy. Estimates of root length density obtained with this method were very high, about an order of magnitude greater than those commonly obtained by core washing. They were however in good agreement with values reported by Stewart [42] or Krebs et al. [25], based on microscopic examination of polished sections, or by Heeraman et al. [22] based on X-ray tomography. Such results indicate that fine roots $(\leq 0.1 \mathrm{~mm}$ in radius), often lost during core washing, may account for up to $50-60 \%$ of the total root length. Finally, the method can be used to get some insight into root system geometry, through quantification of root orientation and branching intensity [34].

Although restricted to 2-dimensions, this method offers new opportunities for the quantification of root system geometry and the interaction of roots with soil structure. As in the case of optical and electronic microscopy, the cost of equipment and labour associated with this method is certainly not negligible. However, this is counterbalanced by the fact that it enables unique characterization of roots and root-soil interplay under field conditions. In addition, this method is quite versatile and with modification can also be used to study root growth dynamics and activity in controlled laboratory experiments (see below Sect. 4.1).

\section{TWO-DIMENSIONAL NON-DESTRUCTIVE/ INVASIVE IMAGING TECHNIQUES}

The idea of observing and measuring living roots through the walls of thin transparent containers (rhizotrons) is quite old and has been implemented in a variety of forms for decades. Coupled with time-lapse photography, it was successfully used by many authors to study root dynamics and how different root zone conditions affect root growth, e.g. [28]. Combined with the use of dye indicators, such an approach proved powerful for visualizing $\mathrm{pH}$ changes along the root system under a range of nutritional conditions [31]. A recent improvement of this kind of techniques is the so-called videodensitometry method which permits the mapping at high spatial resolution of the dynamics of $\mathrm{pH}$ changes occurring along roots [23].

Rhizotrons have also been used in combination with radioisotopes to monitor root induced changes in the rhizosphere. For example, Barber and Ozanne [4] grew plants in ${ }^{45} \mathrm{Ca}$ labeled soil to demonstrate autoradiographically the accumulation/depletion of this element along roots. Finally, although more loosely related to the classical rhizotron concept, we mention two recent applications. The first is a light transmission technique in which projection images of roots in translucent gels are used to obtain unbiased estimates of root lengths, branching patterns and diameter distribution [50]. The second is a high-resolution X-radiographic method used to monitor root tissue differentiation and primordium development in roots grown on synthetic mesh with circulating nutrient solution [6]. In the subsequent sections, we discuss in further detail two new rhizotron based methods we have recently experimented with. 


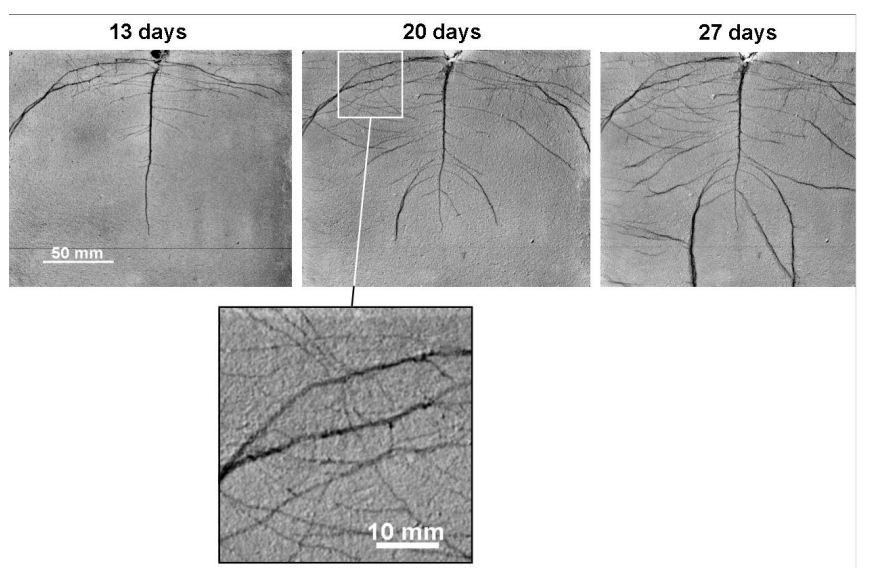

Figure 2. X-ray imaging of live root systems in rhizotrons: series of images taken at weekly interval demonstrating the technique potential for monitoring root growth. The enlarged section of the central image shows the typical spatial resolution: second-order lateral roots $\sim 0.5 \mathrm{~mm}$ in diameter are clearly visible.

\section{1. $X$-ray imaging of live root systems in rhizotrons}

Radiographic techniques, using either, X-ray [51] or neutron sources, e.g. [9], have been successfully used to image and measure live plant roots in soil. Here, we present and discuss the efficacy of X-radiography as a tool for monitoring root growth and response to soil constraints in simplified systems (rhizotrons). The imaging equipment and setup we used to acquire images is basically the same as that described under 2.3 for the imaging of roots in thin sections of impregnated soil. However, to obtain the largest possible field-of-view $(20 \times 25 \mathrm{~cm}$ in our experiments), samples were placed in near to close contact with the image detector resulting in slightly more than $\times 1$ magnification. Exposure times were of the order of 1 minute, with the X-ray source set at $60 \mathrm{kVp}$ and $0.33 \mathrm{~mA}$.

To illustrate this point, Figure 2 shows a sequence of images of the root system of a narrow leafed lupin. The plant was grown in a $1 \mathrm{~cm}$ thick, $50 \times 25 \mathrm{~cm}$ rhizotron, under controlled environmental conditions (12 hours photoperiod with $400 \mu \mathrm{mole} \cdot \mathrm{m}^{-2} \cdot \mathrm{s}$ photosynthetically active radiations, average relative humidity $30-40 \%$, air temperature variable depending on experiment). The rhizotron was filled with a sandy loam soil homogeneously packed at a medium bulk density of $1.4 \mathrm{Mg} \cdot \mathrm{m}^{-3}$. The technique proved very effective at detecting roots and monitoring root growth. Figure 2 illustrates the typical image resolution that can be achieved with such a radiographic system: second-order lateral roots $\sim 0.5 \mathrm{~mm}$ in diameter could be imaged. Figure 3 a demonstrates how this technique can also be used to observe a root's response to soil constraint: upon hitting a dense layer, a lupin plant's taproot intermittently grew upward until its tip found a weaker zone from which it could resume its normal gravitropic course (as indicated by the arrow in Fig. 3a). Along with this perturbed growth pattern, by observing grey level values (light $=$ high), we can also see (Fig. 3b) that the soil around the root was compacted. Although a similar compaction effect was measurable
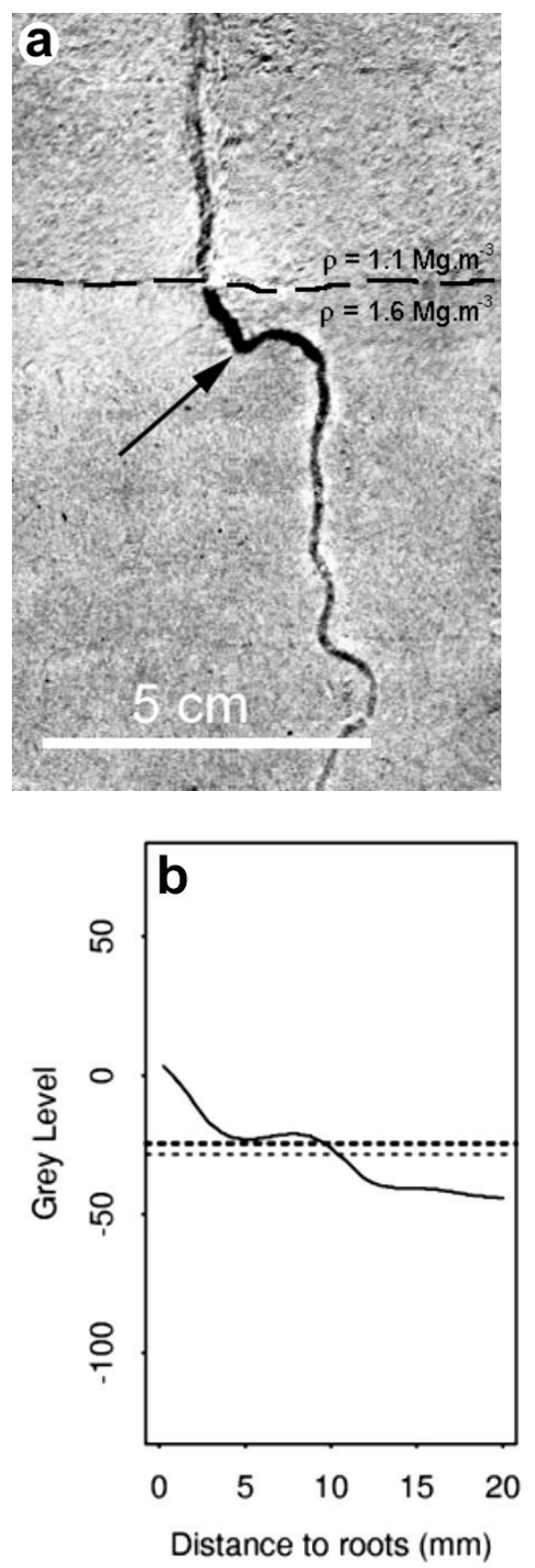

Figure 3. X-ray imaging of live root systems in rhizotrons. (a) Detail of an X-ray image showing the tap root's morphology at the interface between the loose upper layer and the dense lower soil. (b) Plot of grey level values at increasing distances from this impeded taproot: higher (lighter) values indicate root-induced soil compaction (the thin and thick dotted lines are the average grey levels of the soil within $20 \mathrm{~mm}$ and at further distances from the root, respectively).

in loose soil, it was not as obvious as in dense soil (data not shown).

Tidwell and Glass [45] showed how X-ray transmission could be used to measure two-dimensional water saturation fields in thin containers. If some degree of approximation can be tolerated, i.e., if it can be assumed that soil particles remain immobile as the soil moisture content diminishes, then some information about local changes in water content can be 
derived. By applying such an approximation to images of lupin roots growing in homogeneously repacked loamy soil, soil water content was seen to drop more quickly around the lower part of the root system, and that the most intense drying was occurring along a zone $\sim 10 \mathrm{~cm}$ long behind the root tips (Fig. 4a). In a rhizotron with distributed dense aggregates, it was observed (Fig. 4b) that water content changed more rapidly in the loose soil matrix than in the aggregates. This tends to indicate that water was preferentially taken up from the loose matrix, and is consistent with the fact that (i) roots preferentially colonized the matrix and (ii) soil hydraulic conductivity was lower in the aggregates.

Overall, this technique gives access to spatial information on how a root system develops in the soil with time, depending on local environmental conditions such as, e.g. variable soil density and associated water availability. One of the strengths of this method is that it permits one to assess the efficiency of different parts of the root system with respect to water extraction from soil. This method's major limitations are related to the rhizotrons geometry. By constraining root growth within a thin slab of soil, it is likely that root length density is higher than what it would be in a real 3-dimensional system. This in turn may lead to amplified water uptake rates.

\subsection{Light transmission imaging of root water uptake in rhizotrons}

Visible light transmission can be used to quantitatively determine the moisture content within a thin, sand filled slab chamber [11, 45]. In such a 3 phase system made of sand, water and air, the higher the soil moisture content, the better the light transmission. Physically, this is due to the higher refractive index of water than that of air: image contrast is governed by differences in the refractive indices of the airsand and fluid-sand interfaces. One important requirement/ limitation of this technique is that the porous media be translucent and thus the thickness of experimental chamber is generally limited to less than $10 \mathrm{~mm}$.

This principle has been successfully applied to detect the changes in moisture content that develop around roots as they extract water from the sand mixture they grow in $[14,15]$. Rhizotrons $50 \times 100 \mathrm{~cm}$ and $0.4 \mathrm{~cm}$ thick were used to grow plants. These rhizotrons were made of 7 individual compartments separated by Poly Vynil Chloride (PVC) spacers. Plants were grown for 4-6 weeks under controlled environmental conditions $\left(24{ }^{\circ} \mathrm{C} /\right.$ day $20{ }^{\circ} \mathrm{C} /$ night, 13 hours photoperiod, $450 \mu \mathrm{ml} \cdot \mathrm{m}^{-2} \cdot \mathrm{s}$ photosynthetically active radiation, and $60 \%$ relative humidity). A specifically devised mixture of $1.5 \%$ clay and $98.5 \%$ quartz sand (average particle size $175 \mu \mathrm{m}$ ) was chosen for its moisture retention and optical properties. The light source was composed of 19, regularly spaced, $18 \mathrm{~W}$ fluorescent tubes, in front of which was placed an Altuglas ${ }^{\circledR}$ sheet used as a diffuser. Images were captured with a black and white CCD video camera and subsequently digitized into 8-bit format (pixel size $\sim 1.5 \mathrm{~mm}$ ). A calibration chamber was used to derive a calibration curve for point wise estimation of water contents in the images. This calibration chamber was partitioned into 7 separate sections filled with the same sand mixture as the growth container, each at known, different,
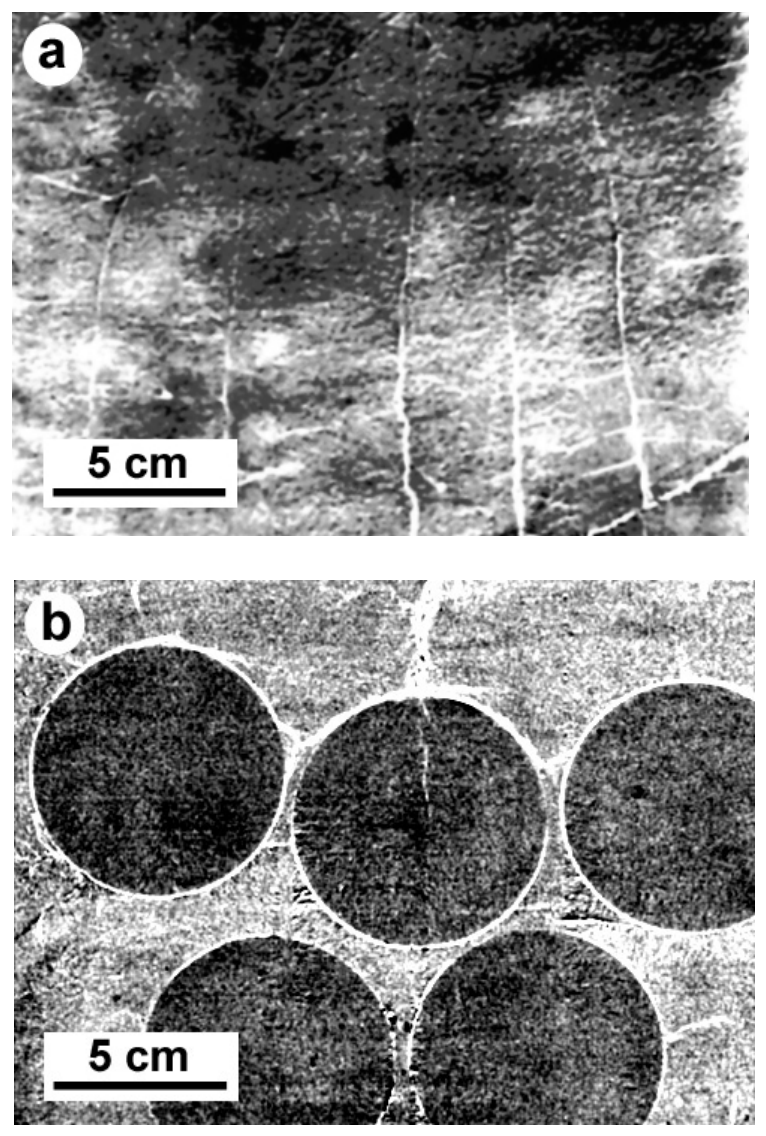

Figure 4. X-ray imaging of live lupin root systems in rhizotrons. (a) Water uptake pattern 4 days after stopping irrigation in loose sandy-loam soil at depths $35-50 \mathrm{~cm}$ (Field of view $\sim 20 \times 15 \mathrm{~cm}$ ): dryer zones (indicated by lighter shades of grey) developed around the lower part of the root system, and the most intense drying was occurring along a zone $\sim 10 \mathrm{~cm}$ long behind the root tips. (b) Water uptake pattern 2 days after stopping irrigation in sandy-loam soil with distributed disks at depths $2-17 \mathrm{~cm}$ (Field of view $\sim 20 \times 15 \mathrm{~cm}$ ): the loose matrix dried up more rapidly (as indicated by lighter shades of grey) than the dense disks. This tends to indicate that water was preferentially taken up from the loose matrix, and is consistent with the fact that (i) roots preferentially colonized the matrix and (ii) soil hydraulic conductivity was lower in the disks.

water content. An image of this chamber was used to derive the function $\theta=f(\mathrm{GL})$, where $\theta$ is the gravimetric moisture content and GL the image grey level. To account for random variations in the light source field and video signal noise, a normalization reference with 8 shades of grey was included in each image's field-of-view.

To illustrate the potential of this technique, Figure 5 presents time series images of drying patterns developing around the root systems of 1 month old lupin and maize plants. A major difference in the water uptake patterns of maize and lupin is due to the different root system architecture of these two species: for lupin, which has a taprooted root system, the drying front moved essentially downward with time. In contrast, with maize, which has a more complex and laterally spread out root system, including seed derived (or axile), 

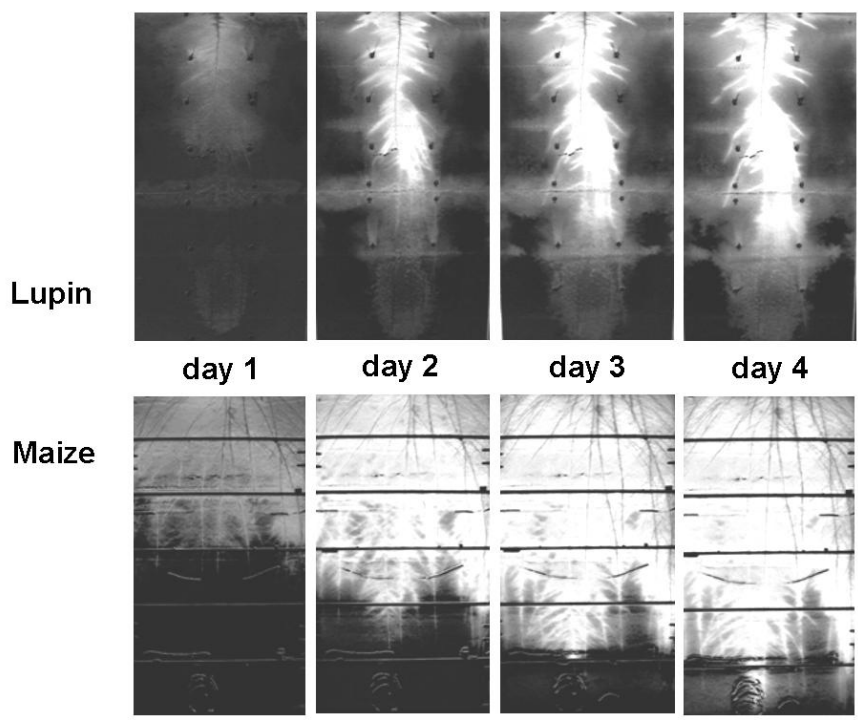

day 2

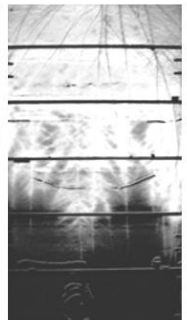

day 3

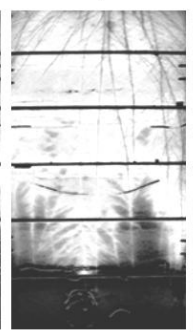

day 4

Maize

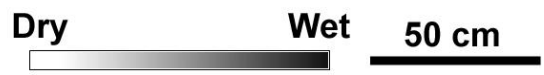

Figure 5. Light transmission imaging of root water uptake in rhizotrons. Time series images of drying patterns developing around the root systems of the lupin (top) and maize (bottom) plants. The lighter the shade of grey, the drier the soil (field of view $\sim 50 \times$ $100 \mathrm{~cm})$.

stem-derived (or nodal) as well as first- and second-order lateral roots [37], the drying front progressed both vertically and laterally (particularly visible along lateral roots at the bottom of the images).

Beside its inherent 2-dimensional nature, this technique's main limitations are that it is restricted to translucent materials and that its sensitivity is reduced at high water content (gravimetric water contents higher than $20 \%$ could not be resolved). However, these weaknesses are significantly offset by uniquely attractive features such as (i) very low cost; (ii) simplicity; (iii) large field-of-view compatible with the root system's size of most field grown annual plants and (iv) high temporal resolution enabling the study of transient water movement around plant roots.

\section{GENERAL DISCUSSION AND CONCLUSIONS}

In this paper, we show that the range of techniques currently available for imaging roots in their environment is quite extensive. Yet, notwithstanding their respective merits, none of the available options is free from restrictions: using a single technique one should not expect to probe more than a small part, at a specific scale, of the wide and complex range of interactions between roots and soil. In this respect, one will need to carefully target a technique or a range of techniques depending on the question(s) to be addressed and the time and resources available.

\subsection{Two-dimensional vs. three-dimensional imaging}

Irrespective of the physical principle involved in the image forming process (i.e. interaction with electromagnetic radiations, particles or nuclear magnetic resonance), all imaging techniques used to study roots fall into two broad categories: the projection or 2-dimensional techniques and the tomographic or 3-dimensional techniques. With projection techniques, physical characteristics of the volume of the sample under scrutiny (attenuation coefficients, refractory index, spin density, relaxation times, etc.) are integrated onto the image plane, whereas tomographic techniques explicitly reveal, through mathematical reconstruction, the spatial distribution of these properties, e.g. [1-3]. In the study of plant roots, considerable effort has been put into using X-ray Computed Tomography (CT) and Nuclear Magnetic Resonance Imaging (NMRI) to investigate water extraction by single plant roots in soil at high [e.g. 17-19, 30] and low [20] water potential. NMRI has also been reported as a suitable technique for studying root system architecture in both artificial, e.g. [41] and natural soils, e.g. [38]. It is noteworthy that NMRI has the potential to unravel not only root architecture and growth dynamics, but also some physiological functions: recent work on water flow through xylem vessels using flow sensitive NMRI [26] indicate that, ultimately, NMRI may allow detailed studies of root activity in soil. X-ray CT was only reported once [22] as a means to reconstruct 3-dimensional plant root distribution and root length density. Due to experimental constraints these studies were most frequently based on somewhat artificial systems including (i) root systems with simple architecture such as radish [18-20]; (ii) pruned root systems [30]; (iii) small soil volumes, typically cores about $10 \mathrm{~cm}$ tall and of the order of $5 \mathrm{~cm}$ in diameter $[16,22,41]$ and (iv) carefully selected growing media (most of the time, sandy mixtures).

Although there is clear evidence in the literature that both CT and NMRI are very valuable techniques for detailed study of e.g. water relations at the root/soil interface, they suffer several limitations the most important of which are, (i) cost; (ii) difficult access to the equipment; (iii) insufficient spatial resolution to detect fine roots when field-of-view compatible with observation of whole root systems; and vice versa (iv) counting times $[16,29]$ which negatively impact on field of view and preclude the study of transient events and (v) in the case of NMRI, interferences with soil paramagnetic nuclei and, to some extent, soil water.

\subsection{Current state of technology and future prospects}

The respective pros and cons of the techniques discussed in this paper are summarized in Table I. There is no doubt, that, because of their importance in e.g. medical imaging applications, the pace at which non-destructive 3-dimensional imaging tools improve will, at least, be steady. Recently developed capabilities of medical X-ray CT technology include fast multi-detector systems allowing shorter scanning times, submillimeter slice imaging which improves resolution, or coregistration of studies acquired in different modalities, at different times, or with different scan conditions which is of great 
Table I. Respective pros and cons of the techniques discussed in the paper. The disk size is proportional to the suitability of a given technique for a specific purpose.

\begin{tabular}{|c|c|c|c|c|c|}
\hline & \multicolumn{2}{|c|}{ 2D destructive/invasive } & \multicolumn{2}{|c|}{ 2D non-destructive/non invasive } & \multirow{2}{*}{$\begin{array}{c}\text { 3D } \\
\text { 3D imaging } \\
(\mathrm{CT}, \mathrm{NMRI})\end{array}$} \\
\hline & $\begin{array}{c}\text { Microscopy of } \\
\text { undisturbed samples }\end{array}$ & $\begin{array}{l}\text { X-ray imaging of } \\
\text { undisturbed samples }\end{array}$ & $\begin{array}{l}\mathrm{X} \text {-ray imaging of live } \\
\text { roots in rhizotrons }\end{array}$ & $\begin{array}{l}\text { Light Transmission } \\
\text { through rhizotrons }\end{array}$ & \\
\hline $\begin{array}{l}\text { Root detection } \\
\text { (spatial resolution) }\end{array}$ & $<100 \mu \mathrm{m}$ & $\geq 25 \mu \mathrm{m}$ & $\geq 500 \mu \mathrm{m}$ & $\geq 1500 \mu \mathrm{m}$ & $\geq 150 \mu \mathrm{m}$ \\
\hline Field-of-view & Up to $55 \times 55 \mathrm{~mm}$ & $\mathrm{Up}$ to $70 \times 70 \mathrm{~mm}$ & $\begin{array}{l}\text { Of the order of } \\
200 \times 250 \mathrm{~mm}\end{array}$ & $\begin{array}{l}\text { Of the order of } \\
500 \times 1000 \mathrm{~mm}\end{array}$ & $\begin{array}{l}\text { 2D slices typically } \\
50 \times 50 \mathrm{~mm}\end{array}$ \\
\hline $\begin{array}{l}\text { Root length } \\
\text { measurement }\end{array}$ & & & 0 & 0 & \\
\hline $\begin{array}{l}\text { Root spatial } \\
\text { distribution }\end{array}$ & & & 0 & & \\
\hline Root/soil contact & & 0 & & - & $\cdot$ \\
\hline $\begin{array}{l}\text { Root/soil structure } \\
\text { interactions }\end{array}$ & & & 0 & $\cdot$ & 0 \\
\hline $\begin{array}{l}\text { Water uptake and } \\
\text { soil/root water relations }\end{array}$ & 0 & - & & & \\
\hline $\begin{array}{l}\text { Overall root system } \\
\text { development and } \\
\text { architecture }\end{array}$ & - & - & & & \\
\hline $\begin{array}{l}\text { Suitability for field } \\
\text { based studies }\end{array}$ & & & • & & 0 \\
\hline Real time & & • & & & \\
\hline Availability & & & & & 0 \\
\hline Cost & $\begin{array}{l}\text { Moderate (optical) } \\
\text { to high (EM) }\end{array}$ & $\begin{array}{c}\text { Moderate to high } \\
\text { (depending on image } \\
\text { detector) }\end{array}$ & $\begin{array}{c}\text { Moderate to high } \\
\text { (depending on image } \\
\text { detector) }\end{array}$ & Very low & $\begin{array}{c}\text { Very high } \\
\text { (unless access to } \\
\text { existing facility) }\end{array}$ \\
\hline
\end{tabular}

interest for the study of dynamics processes. As an illustration of what such technological advances have to offer to the study of whole root systems, we present here (Fig. 6), the image of the root system of a 6 weeks old chickpea plant obtained by A. McNeill (University of Adelaide, Australia), using a stateof-the-art Toshiba Aquilion ${ }^{\mathrm{TM}}$ helical CT scanner, at a resolution of $0.5 \mathrm{~mm}$.
Despite these recent advances, root scientists interested in non-destructive/non-invasive observation of plant roots and their environment still face a trade-off between spatial resolution, field-of-view and 3-dimensionality: with the current state of the technology it is possible to have any two. This is a major limitation, considering that unconstrained root systems are 3dimensional entities which include many fine roots, and which 


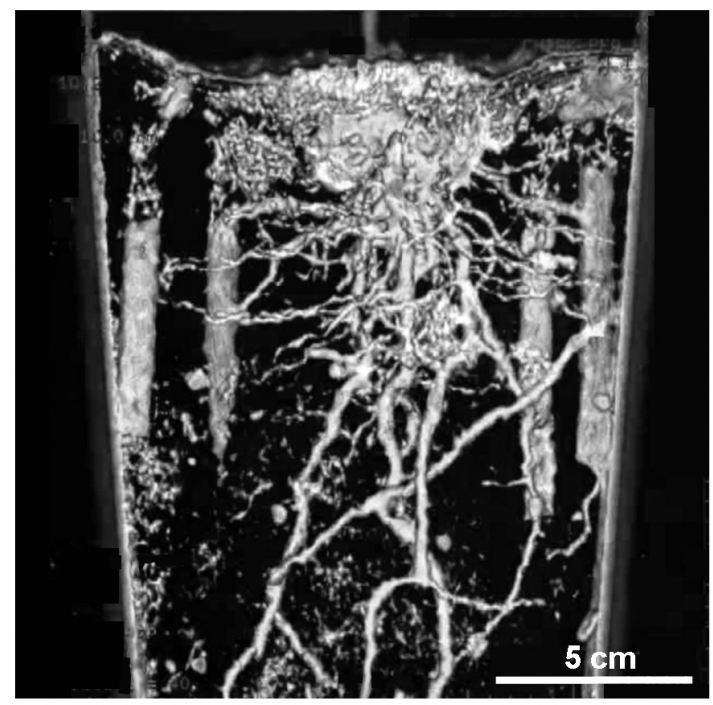

Figure 6. Three-dimensional rendering of the root system of a 6 weeks old chickpea plant obtained by Dr. A. McNeill (University of Adelaide, Australia), using a Toshiba Aquilion ${ }^{\mathrm{TM}}$ Real Time helical CT scanner, at a resolution of $0.5 \mathrm{~mm}$.

explore large volumes of soil. We conclude that, while fully appropriate 3D imaging tools will ultimately become available, in the meantime, simpler two-dimensional techniques should be considered for observing roots in their environment. In particular, we show that 2D imaging techniques, based on either visible light or X-ray attenuation through thin growing containers (rhizotrons), can be quite useful to study the functioning of whole root systems.

Additionally, one must choose between non-destructive/ non-invasive and destructive/invasive techniques. Obviously, the former enable the study of live plants, which is most valuable when dealing with dynamic processes such as water uptake. On the other hand, although destructive investigations only provide a static, 'snapshot-like' view of a sample, they certainly represent a valuable option for small-scale study of the interplay between roots and soil, in particular under field conditions. We conclude that, microscopic or high-resolution $\mathrm{X}$-ray imaging of roots in undisturbed soil samples have a considerable value because they can provide, at a scale which is not accessible by any other means, essential information on complex interactions between roots and soil structure.

Acknowledgements: Part of the experimental work described in this paper was financially supported by the Grains Research and Development Corporation, Australia. Colin McLachlan of CSIRO Land and Water, Canberra helped with fieldwork and in the preparation of the thin section. Annagret Fier of Osnabrueck University, Germany, helped with X-ray imaging of live roots. Drs. Ann McNeil, University of Adelaide, Australia, and Yves Coquet, Institut National Agronomique, Grignon, France, are gratefully acknowledged for helpful comments and discussions.

\section{REFERENCES}

[1] Anderson S.H., Hopmans J.W., Tomography of soil-water-root processes. Proceedings of a symposium, Minneapolis, Minnesota, USA, 4 Nov. 1992, Earthscan Publications Ltd, London, USA, 1994, $148 \mathrm{p}$.
[2] Asseng S., Aylmore L.A.G., McFall J.S., Hopmans J.W., Gregory P.J., Computer-assisted tomography and magnetic resonance imaging, in: Smit A.L., Bengough A.G., Engels C., Van Noordwijk M., Pellerin S., Van de Geijn S.C. (Eds.), Roots Methods, Springer-Verlag, Berlin Heidelberg, 2000, pp. 343-363.

[3] Aylmore L.A.G., Use of computer-assisted tomography in studying water movement around plant roots, Adv. Agron. 49 (1993) 2-54.

[4] Barber S.A., Ozanne P.G., Autoradiographic evidence for the differential effect of four plant species in altering the calcium content of the rhizosphere soil, Soil Sci. Soc. Am. Proc. 34 (1970) 635-637.

[5] Barley K.P., The effects of mechanical stress on the growth of roots, J. Exp. Bot. 13 (1954) 95-110.

[6] Bidel L.P.R., Mannino M.R., Rivière L.M., Pagès L., Tracing root development using the soft X-ray radiographic method, as applied to young cuttings of western red cedar (Thuja plicata), Can. J. Bot. 77 (1999) 348-60.

[7] Bresson L.M., Moran C.J., High-resolution bulk density images, using calibrated X-ray radiography of impregnated soil slices, Soil Sci. Soc. Am. J. 62 (1998) 299-305.

[8] Bruand A., Cousin I., Nicoullaud B., Duval O., Bégon J.C., Backscattered electron scanning images of soil porosity for analyzing soil compaction around roots, Soil Sci. Soc. Am. J. 60 (1996) 895-901

[9] Bushamuka V.N., Zobel R.W., Differential genotypic and root type penetration of compacted soil layers, Crop Sci. 38 (1998) 776-781.

[10] Clothier B.E., Green S.R., Roots: the big movers of water and chemicals in soil, Soil Sci. 162 (1997) 534-543.

[11] Darnault C.J.G., Throop J.A., DiCarlo D.A., Rimmer A., Steenhuis T.S., Parlange J.Y., Visualization by light transmission of oil and water contents in transient two-phase flow fields, J. Contam. Hydrol. 31 (1998) 337-348.

[12] De Willigen P., Van Noordwijk M., Roots, plant production and nutrient use efficiency, Ph.D. Thesis, Agricultural University of Wageningen, The Netherlands, 1987, $282 \mathrm{p}$.

[13] Devereux-Joslin J., Wolfe M.H., Disturbances during minirhizotron installation can affect root observation data, Soil Sci. Soc. Am. J. 63 (1999) 218-221.

[14] Garrigues E., Doussan C., Debroux M., Plant water uptake and transfer- from the single root to the root system scale: experimental study, Geophysical Research Abstract, Vol. 2, Congrès EGS, $25^{\mathrm{e}}$ assemblée, Nice, Avril 2000, CD-ROM édition, ISSN: 10297006, 2000.

[15] Garrigues E., Doussan C., A comparison of root water uptake between maize and Lupin: Experimental study, $26^{\mathrm{e}}$ colloque de l'EGS Nice, Mars 2001, Geophysical Research Abstracts, Vol. 3, CD-ROM édition, ISSN: 1029-7006, 2001.

[16] Gregory P.J., Hinsinger P., New approaches to studying chemical and physical changes in the rhizosphere: an overview, Plant and Soil 211 (1999) 1-9.

[17] Hainsworth J.M., Aylmore L.A.G., The use of computer assisted tomography to determine spatial distribution of soil water content, Aust. J. Soil Res. 21 (1983) 435-443.

[18] Hainsworth J.M., Aylmore L.A.G., Water extraction by single plant roots, Soil Sci. Soc. Am. J. 50 (1986) 841-848.

[19] Hamza M.A., Aylmore L.A.G., Soil solute concentration and water uptake by single lupin and radish plant roots. I. Water extraction and solute accumulation, Plant and Soil 145 (1992) 187-196.

[20] Hamza M.A., Anderson S.H., Aylmore L.A.G., Studies of soil water drawdowns by single radish roots at deacreasing soil water content using computer-assisted tomography, Aust. J. Soil Res. 39 (2001) 1387-1396.

[21] Heeraman D.A., Juma N.G., A comparison of minirhizotron, core and monolith methods for quantifying barley (Hordeum vulgare 
L.) and fababean (Vicia faba L.) root distribution, Plant and Soil 148 (1993) 29-41.

[22] Heeraman D.A., Hopmans J.W., Clausnitzer V., Three dimensional imaging of plant roots in situ with X-ray computed tomography, Plant and Soil 189 (1997) 167-179.

[23] Jaillard B., Ruiz L., Arvieu J.C., pH mapping in transparent gel using color indicator videodensitometry, Plant and Soil 183 (1996) $85-95$.

[24] Kooistra M.J., Schoonderbeek D., Boone F.R., Veen B.W., Van Noordwijk M., Root-soil contact of maize, as measured by a thinsection technique. II. Effects of soil compaction, Plant and Soil 139 (1992) 119-129.

[25] Krebs M., Kretzschmar A., Babel U., Chadoeuf J., Goulard M., Investigations on distribution patterns in soil: basic and relative distributions of roots, channels and cracks, Dev. Soil Sci. 22 (1994) 437-449.

[26] Kuchenbrod E., Landek M., Thurmer F., Haase A., Zimmermann U., Measurement of water flow in xylem vessels of intact maize plants using flow-sensitive NMR imaging, Bot. Acta 109 (1996) 184-186.

[27] Livesley S.J., Stacey C.L., Gregory P.J., Buresh R.J., Sieve size effects on root length and biomass measurements of maize (Zea mays) and Grevillea robusta, Plant and Soil 207 (1998) 183-193.

[28] Lonkerd W.E., Ritchie J.T., Split root observation system for root dynamics studies, Agron. J. 71 (1979) 519-522.

[29] Macedo A., Crestana S., Vaz C.M.P., X-ray microtomography to investigate thin layers of soil clod, Soil Tillage Res. 49 (1998) 249-253.

[30] MacFall J.S., Johnson G.A., Use of magnetic resonance imaging in the study of plants and soils, in: Anderson S.H., Hopmans J.W (Eds.), Tomography of soil-water-root processes, Proceedings of a symposium, Minneapolis, Minnesota, USA, 4 Nov. 1992, Earthscan Publications Ltd, London, USA, 1994, pp. 99-114.

[31] Marshner H., Römheld V., Horst W.J., Martin P., Root-induced changes in the rhizosphere: Importance for the mineral nutrition of plants, Z. Pflanzenernähr. Bodenk. 149 (1986) 441-456.

[32] McCully M.E., Roots in soil: unearthing the complexities of roots and their rhizospheres, Annu. Rev. Plant Physiol. Plant Mol. Biol. 50 (1999) 695-718.

[33] McCully M.E., Water efflux from the surface of field-grown roots. Observations by cryoscanning electron microscopy, Physiol. Plant. 95 (1995) 217-224.

[34] Moran C.J., Pierret A., Stevenson A.W., X-ray absorption and phase contrast imaging to study the interplay between plant roots and soil structure, Plant and Soil 23 (2000) 99-115.

[35] Passioura J.B., Roots and water economy of wheat, in: Day W., Atkin R. (Eds.), Wheat growth and modelling, Plenum Press, New York, 1985, pp. 185-198.
[36] Passioura J.B., Soil structure and plant growth, Aust. J. Soil Res. 29 (1991) 717-728.

[37] Pellerin S., Pagès L., Evaluation in field conditions of a threedimensional architectural model of the maize root system: comparison of simulated and observed horizontal root maps, Plant and Soil 178 (1996) 101-112.

[38] Rogers H.H., Bottomley P.A., In situ nuclear magnetic resonance imaging of roots: influence of soil type, ferromagnetic particle content, and soil water, Agron. J. 79 (1987) 957-965.

[39] Santos D., Murphy S.L.S., Taubner H., Smucker A.J.M., Horn R. Uniform separation of concentric surface layers from soil aggregates, Soil Sci. Soc. Am. J. 61 (1997) 720-724.

[40] Soil Survey Staff, Keys to soil taxonomy, U.S.D.A., Natural Resources Conservation Service, 1998.

[41] Southon T.E., Jones R.A., NMR imaging of roots: methods for reducing the soil signal and for obtaining a 3-dimensional description of the roots, Physiol. Plant. 86 (1992) 322-328.

[42] Stewart J.B., The spatial distribution of plant roots and their interaction with soil structure, Ph.D. Thesis, The University of Sydney, 1997

[43] Stewart J.B., Moran C.J., Wood J.T., Macropore sheath: quantification of plant root and soil macropore association, Plant and Soil 211 (1999) 59-67.

[44] Stirzaker R.J., Passioura J.B., Wilms T., Soil structure and plant growth - impact of bulk density and biopores, Plant and Soil 185 (1996) 151-162.

[45] Tidwell V.C., Glass R.J., X-ray and visible light transmission for laboratory measurement of two-dimensional saturation fields in thin-slab systems, Water Resour. Res. 30 (1994) 2873-2882.

[46] Tiunov A.V., Scheu S., Microbial respiration, biomass, biovolume and nutrient status in burrow walls of Lumbricus terrestris L. (Lumbricidae), Soil Biol. Biochem. 31 (1999) 2039-2048.

[47] Van Noordwijk M., Schoonderbeek D., Kooistra M.J., Root-soil contact of field-grown winter wheat, Geoderma 56 (1993) 277 286.

[48] Watt M., McCully M.E., Canny M.J., Formation and stabilization of rhizosheaths in Zea mays L. Effect of soil water content, Plant Physiol. 106 (1994) 179-186.

[49] Wilkins S.V., Gureyev T.E., Gao D., Pogany A., Stevenson A.W., Phase-contrast imaging using polychromatic hard X-rays, Nature 384 (1996) 335-338.

[50] Wulfsohn D., Nyengaard J.R., Gundersen H.J.G., Cutler A.J., Squires T.M., Non-destructive, stereological estimation of plant root lengths, branching pattern and diameter distribution, Plant and Soil 214 (1999) 15-26.

[51] Zwiggelaar R., Bull C.R., Mooney M.J., Czarnes S., The detection of "soft" materials by selective energy X-ray transmission imaging and computer tomography, J. Agric. Eng. Res. 66 (1997) 203-212. 